\title{
SIMULATING THE STRESS AND STRAIN BEHAVIOR OF LOESS VIA SCC MODEL
}

\author{
M.D. LIU \\ Faculty of Engineering, University of Wollongong, Australia, martindl@uow.edu.au \\ J. LIU \\ Faculty of Engineering, University of Wollongong, Australia, jl370@uow.edu.au \\ S. HORPIBULSUK \\ Civil Engineering, Suranaree University of Technology, Thailand, suksun@g.sut.ac.th \\ W. HUANG \\ College of Mechanics and Materials, Hohai University, China, wh670@hhu.edu.cn
}

The behaviour of collapsible soils (loess) is studied in this paper. Simulations of the stress and strain behaviour of the soil are made via the theoretical framework of Structured Cam Clay, with the effect of glutinous ingredient in loess suggested to be modelled as cementation effect. Based on the simulations, the capacity of the model for representing the behaviour loess is investigated, and discussions on modelling the behaviour of collapsible soil in general are given.

\section{INTRODUCTION}

Loess, found in many parts of the world, has been proved to be engineering challenge because of its collapsible nature [e.g., 1, 2, 3]. The soil possesses features of structured soil, and undergoes dramatically destructuring when it is wetted, disturbed, or loaded. Compared with natural clays, the study on the collapsible nature of the mechanical properties of loess both laboratory tests and theoretical modelling are relatively less investigated. Recently, there have been useful advances in constitutive modelling of natural soft soils [e.g., 4, 5]. In this paper, the mechanical properties of loess are investigated. A primary study is performed on the capability of the Structured Cam Clay modified for cementation effect proposed by Horpibulsuk et al [6] for representing the behaviour of loess and some discussions on model parameters for loess are also made.

\section{MECHANICAL PROPERTIES OF NATURAL LOESS}

Loess is structured soil and frequently strongly structured. The original structure of loess may undergo dramatically destructuring when it is wetted, loaded or disturbed, normally leading to the reduction of the strength and stiffness of the soil. Based on the examination of some available experimental data [e.g., 1, 2, 3, 7, 8], some special mechanical properties of loess are found.

(1) The structural strength of loess is mainly contributed by cementation among soil. However, the cementation link can be dissolved in water; thus cohesion strength diminishes when the soil is fully saturated. The cementational strength can also be removed by loading. (2) Qualitative similarity in the mechanical behaviour between loess and natural clays can be seen as follows. Firstly, the voids ratio for a natural loess is higher than that of the reconstituted soil of the same mineralogy and the virgin yielding stress of the soil is also higher that of the corresponding 
reconstituted soil. Secondly, the stress and strain behaviour of the structured loess appear to be asymptotic to the curve for the reconstituted soil, i.e. the influence of soil structure tends to diminish with loading. (3) A basic feature of the behaviour of a loess is its dependence on the degree of saturation of the soil.

\section{STRUCTURED CAM CLAY MODEL EXTENDED FOR CEMENTATION EFFECT}

Because loess possesses both cementation structure and particle-arrangement structure, the Structured Cam Clay Model Extended for cementation effect is employed as a base to describe the soil. A brief introduction of the extended model is given below, and details of the model can be found in papers by Liu and Carter [9] and Horpibulsuk et al [6].

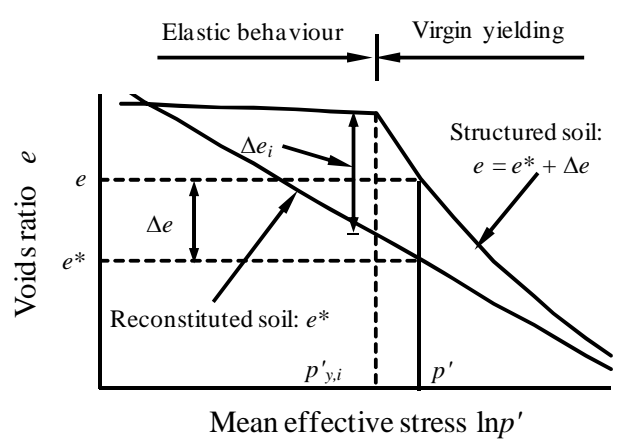

(a) Compression behaviour of structural soils

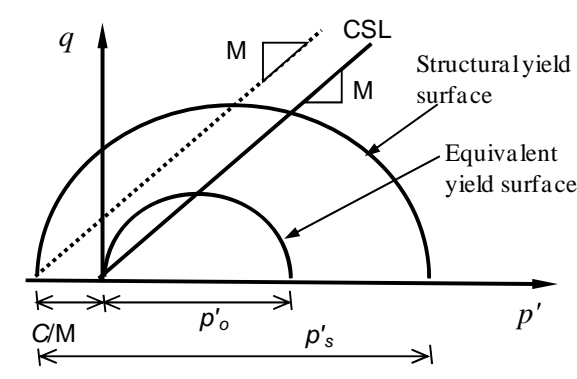

(b) Structural and equivalent yield surfaces

Figure 1. Materialization for the Structured Cam Clay Model

\section{Modification of the mean effective stress cementation}

A fundamental assumption in the extending the SCC model for the effect of cementation is taken into consideration as the reinforcement of the confining mean effective stress; and a modified mean stress parameter is proposed as follows,

$\bar{p}^{\prime}=p^{\prime}+C / M$

where $p^{\prime}$ is the mean effective stress, $\mathrm{M}$ is the slope of the failure envelope of cemented clay, and $C$ is a parameter related to the shear strength contributed by cementation. It should be pointed out that $C$ is generally not constant, but a function of soil structure. The cohesion strength of loess is strongly dependent the degree of saturation. In this study, the value for $C$ for loess with a given saturation is identified. Then it is assumed that the value fo $C$ remains constant before the peak strength. After peak failure state, $C$ gradually decreases due to the crushing of soil structure, and finally $C=0$ will be reached at a critical state of deformation.

\section{Material idealization}

In the extended SCC model, cemented clay is idealized as an isotropic material with elastic and virgin yielding behaviour. The yield surface varies isotropically with plastic volumetric deformation. Soil behaviour is assumed to be elastic for any stress excursion inside the current structural yield surface. Virgin yielding occurs for a stress variation originating on the structural 
yield surface and causing it to change. During virgin yielding, the current stress of a cemented clay stays on the structural yield surface. The idealization of the mechanical behaviour of cemented clays is illustrated in Figure 1. In this figure, $e$ represents the voids ratio for a cemented clay, $e^{*}$ is the voids ratio of the reconstituted clay at same stress state with the same yield surface, $p_{y, i}^{\prime}$ is the mean effective stress at which virgin yielding of the cemented soil begins, and $\Delta e$, the additional voids ratio, is the difference in voids ratio between the cemented clay and the reconstituted clay at the same stress state. Hence, the virgin compression behaviour of a cemented soil can be expressed by the following equation proposed by Liu and Carter [11],

$e=e^{*}+\Delta e=e^{*}+\left(\Delta e_{i}-c\right)\left(\frac{p_{y, i}^{\prime}+C / M}{\bar{p}^{\prime}}\right)^{b}+c$

where $b$ and $c$ are soil parameters describing the additional voids ratio sustained by cementation. $\Delta e_{i}$ is the value of the additional voids ratio at the start of virgin yielding (Figure 1a). Parameter $c$ is that part of the additional voids ration that can not be removed completely by loading,

The yield surface of a cemented clay in $p^{\prime}-q$ space is also assumed to be elliptical and is described as (Figure 1b). The size of the yield surface is denoted as $p_{s}^{\prime}$.

\section{Elastic behaviour}

For stress excursions within the yield surface, only elastic deformation occurs. For simplicity, elastic deformation of cemented clay is assumed to be described by Hooke's law, i.e.,

$$
d \varepsilon_{v}^{e}=\frac{3(1-2 v)}{E} d p^{\prime} \quad d \varepsilon_{d}^{e}=\frac{2(1+v)}{3} \frac{d q}{E}
$$

where $v$ is the Poisson's ratio and $E$ is the Young's modulus.

\section{Virgin yielding behaviour}

For stress states on the yield surface and with $d p_{s}^{\prime}>0$, virgin yielding occurs. The plastic volumetric strain increment for the original SCC model was derived from the assumption that both hardening and destructuring of clays are dependent on volumetric deformation, with a consideration of the destructuring associated with shearing [e.g., 9, 10]. The incremental stress and strain relationship of the Structured Cam Clay is

$$
\begin{aligned}
& d \varepsilon_{v}=d \varepsilon_{v}^{e}+\left\{(\lambda *-\kappa)+b\langle\Delta e-c\rangle\left[1+\frac{\gamma \bar{\eta}}{\mathrm{M}-\bar{\eta}}\right]\right\} \frac{d p_{s}^{\prime}}{(1+e) p_{s}^{\prime}} \\
& d \varepsilon_{d}=d \varepsilon_{d}^{e}+\frac{2 \bar{\eta}}{\left|\mathrm{M}^{2}-\bar{\eta}^{2}\right|+\omega\left|1-\sqrt{p_{o}^{\prime} / p_{s}^{\prime}}\right|} \times\left\{\left(\lambda^{*}-\kappa\right)+b\langle\Delta e-c\rangle\left[1+\frac{\gamma \bar{\eta}}{\mathrm{M}-\bar{\eta}}\right]\right\} \frac{d p_{s}^{\prime}}{(1+e) p_{s}^{\prime}}
\end{aligned}
$$


where $\lambda^{*}$ and $\kappa^{*}$ are the compression and the swelling indices of reconstituted clay, respectively, $\gamma$ is a soil parameter describing the destructuring associated with shearing, $\omega$ is a model parameter, and $p^{\prime}{ }_{o}$ is the size of the equivalent yield surface with consideration of the influence of $c$, the part of the additional voids ration that can not be removed completely by loading [6].

\section{Softening behavior and breakdown of cementation}

Based on experimental observation, the softening behaviour for cemented clay occurs after the soil reaches the peak strength state $(\bar{\eta}=\mathrm{M}$ and $\Delta e \neq 0)$. The crushing of soil-cementation structure also takes place during this stage. For simplicity, it is assumed that the crushing of soilcementation structure commences after the peak state to reach the final critical state of deformation. During crushing, the effective stress state stays on the line defined by M but may travel along the line either upwards or downwards, depending on hardening or softening, respectively. Based on trial and error, the function for the crushing of soil-cementation structure is proposed,

$d C=-2\left(\frac{C}{C_{\text {in }}}\right) \frac{\left|d p_{s}^{\prime}\right|}{\sqrt{\left(\frac{q}{p^{\prime}}-\mathrm{M}\right)}}$

where $C_{\text {in }}$ is the value of the initial cementation strength.

\section{SIMULATING THE BEHAVIOUR OF MA LAN LOESS}

In this section, the Structured Cam Clay Model Extended for cementation effect is employed to simulate the behaviour of Ma Lan loess. The experimental data were reported by Li and Yao [8]. Value of model parameters identified for simulations are listed in Table 1.

Table 1 Values of model parameters of Malan loess

\begin{tabular}{|c|c|c|c|c|c|c|c|c|}
\hline$\lambda^{*}$ & $\kappa^{*}$ & $\mathrm{M}^{*}$ & $e_{I C} *$ & $v^{*}$ & $b$ & $C$ & $\omega$ & $\gamma$ \\
\hline 0.122 & 0.03 & 0.98 & 1.403 & $\mathbf{0 . 3}$ & 1 & 30 & $\mathbf{1}$ & $\mathbf{1}$ \\
\hline
\end{tabular}

Because limit data are available for the soil from this paper and previous publications, the authors are unable to determine the size of the initial yield surface $p_{y, i}^{\prime}$. By trial and error, the an empirical equation is proposed to determine $p_{y, i}^{\prime}$ based on the undrained peak shear strength $q_{\text {peak }}$.

$$
p_{y, i}^{\prime}=\frac{1.85 q_{p e a k}}{\mathrm{M}^{*}}
$$

A comparison of the effective stress paths for Malan loess in undrained conventional triaxial tests between simulation and test results are shown in Figures 2 and 3. Six tests are simulated and compared with experimental observations. They are four shearing tests starting from isotropic stress states, and 2 tests from anisotropic stress states. The confining stresses vary from $200 \mathrm{kPa}$ to $750 \mathrm{kPa}$. It can be seen that the general features of the effective stress paths of the loess are described well both qualitatively and quantitatively. The simulated deviatoric stress and strain relationship is shown in Figure 3, which is consistent qualitatively with experimental observation 
[2, 8]. It is seen that overall model simulations are in consistency reasonable well with experimental observation. From this study, the following points on modelling the stress and strain relationship of loess are observed.

(1) Unlike that of reconstituted soils, there are two additional factors contributing the softening for loess: (a) the crushing of soil structure, and (b) decementation. For the crushing of soil structure, stress paths keep the same stress ratio as $\mathrm{M}^{*}$ and move downward along the critical state line. For decementation, cementation strength $\mathrm{C}$ reduces gradually to zero and the stress ratio also decreases. It is seen here that the softening on loess is largely influenced by decementation. (2) It may be concluded from the comparison that the basic features of the behaviour of loess can be captured by the Structured Cam Clay with cementation in particular, though more work is needed on aspects such as the determination of model parameters, the variation of cohesion with saturation and the removal of soil structure by loading. (3) It can also be seen from the behaviour of loess can be captured by conventional elastoplastic models in general, and the two key factors in such a model are the structure of the soil constituents and the suction force.

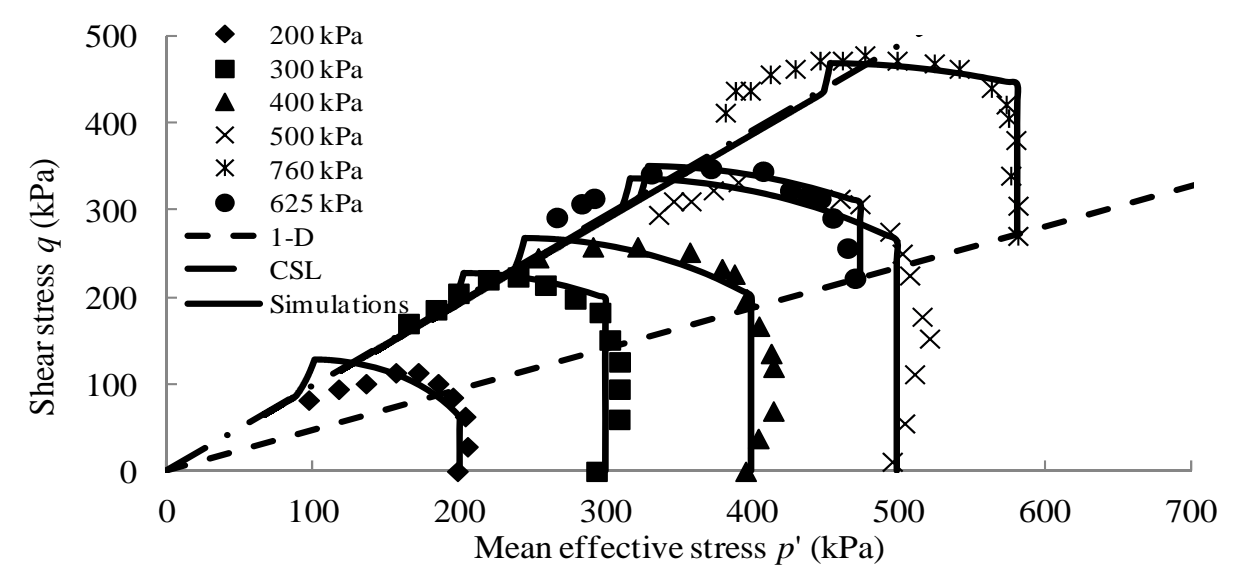

Fig 2. Effective stress paths for Malan loess measured and simulated

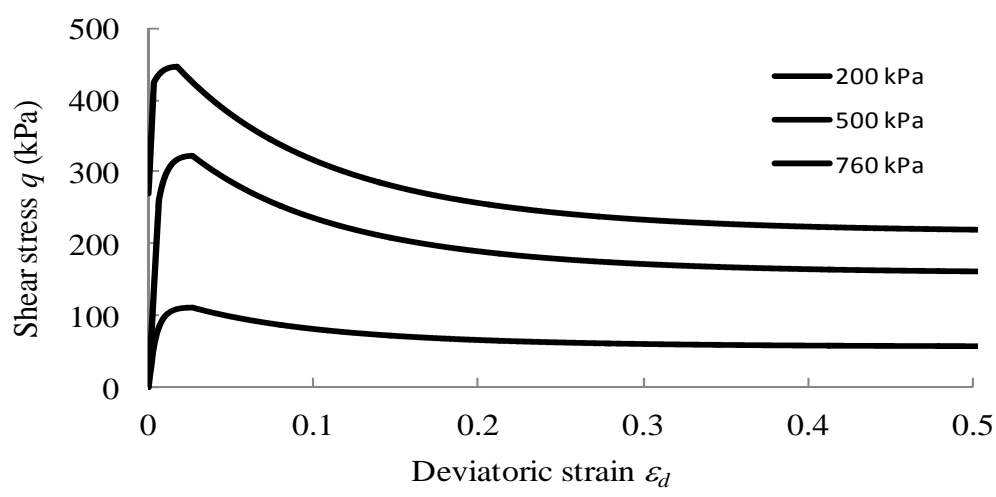

Fig 3. Deviatoric stress and strain relationship of Ma Lan loess simulated 


\section{CONCLUSION}

Mechanical properties of loess are investigated and simulations of the stress and strain behaviour of the soil are made via the the thoretical framework of the Structured Cam Clay, and these simulations were compared with experimental observation. It is concluded that accurate prediction of the behaviour of loess is highly challenging because of complexity of the cementation amoung soil particles and collapsible nature of the structure with water as well as loading. It is seen that the Structured Cam Clay can provide approximate estimation of the behaviour of the loess. Therefore loess is a frictional material and its behaviour is dependent on the arrangement of and bonding amoung soil partices, essentially the same as other natural clays. To improve the accuracy of the simulation, further research within the Structured Cam Clay is needed in accurate representation of the development and removal of the cementation and structure of the soil with time, water and loading. An empirical equation for estimating the size of the initial structural yield surface is also suggested.

\section{REFERENCES}

[1] Chen C., Zhu Z., and Gao P, "Research on relationship between structure and deformation property of intact loess”, Rock and Soil Mechanics, Vol. 27, No. 11, (2006),pp 1892-1896.

[2] Shao S., Luo A., Yu Q., and Zhou F., "Structural damage properties of $\mathrm{Q}_{3}$ loess under triaxial loading and moistening”, Chinese Journal of Geotechnical Engineering, Vol. 28, No. 12, (2006),pp.2078-2081.

[3] Leroueil S. and Hight D., "Compacted soils: from physics, to mechanics to hydraulic and mechanical behavior”. First Pan-American Conf. on Unsaturated Soils, Cartagena de Indias, Colombia, (2013).

[4] Gens, A. and Nova, R., "Conceptual bases for constitutive model for bonded soil and weak rocks”. Geotechnical Engineering of Hard Soil-Soft Rocks, Balkema, (1993).

[5] Taiebat M., Dafalias Y. F., Peek R., "A destructuration theory and its application to SANICLAY model”, Int. J. for Numerical and Analytical Methods in Geomechanics. Vol. 34, No. 10, (2010),pp. 1009-1040.

[6] Horpibulsuk S., Liu M. D., Liyanapathirana S. and Suebsook J., "Behaviour of cemented clay simulated via the theoretical framework of the SCC model”, Computer and Geotechnique, Vol. 37, No. 1, (2010),pp.1-9.

[7] Hu Z., Shen Z., and Xie D., "Deformation properties of structural loess”, Chinese Journal of Rock Mechanics and Engineering, Vol. 23, No. 24, (2004),pp.4143-4145.

[8] Li J. and Yao Y., "Critical state model of Ko comsolidated structure loess”, J.Xi'an Univ. of Arch. \& Tech.(Natural Sience Edition), Vol. 42, No. 4, (2009),pp.533-537.

[9] Liu M. D. and Carter J. P., “Structured Cam Clay Model”, Canadian Geotechnical Journal. Vol.39, No. 6, (2002),pp.1313-1332.

[10] Liu M. D. and Carter J. P., “The volumetric deformation of natural clays”, International Journal of Geomechanics, ASCE, Vol. 3, No. 3/4, (2003),pp.236-252.

[11] Liu M. D. and Carter J. P. (2000), "Modelling the destructuring of soils during virgin compression”, Géotechnique, Vol. 50(4), pp.479-483. 